\title{
The Influence of Torsional Moments on the Elastoplastic Interaction Curves of a Symmetrical I Cross-Section
}

\author{
George T. Michaltsos* and Ioannis G. Raftoyiannis
}

Department of Civil Engineering, National Technical University of Athens, Athens 15780, Greece

\begin{abstract}
This work deals with the influence of the pure torsional (St. Venant) moment on deriving the elastoplastic interaction curves of internal forces and moments of a symmetrical I-section. The problem is addressed employing the exact theory of torsion. The simultaneous action of normal and shear stresses due to axial forces as well as bending and torsional moments is thoroughly investigated and the results are compared to the provisions of Eurocode 3 (EC3). Is has been found that the code's provisions are partly simplified formulae leading in most cases to uneconomic design.
\end{abstract}

Keywords: Elastoplasticity, plastic torsion, interaction curves.

\section{INTRODUCTION}

Each cross-section of a structural member (beam or column) is subjected to a set of six internal forces and moments due to bending, pure torsion or axial distress and two more forces caused by warping of the cross-section (bimoment and warping torsion). Although the stress-state problem can be easily formulated for the bending moments and forces, it becomes rather difficult if one attempts to formulate it taking into account the torsion moment and apply the exact theory of torsion $[1,2]$. On the other hand the usually applied simplifications for the torsional stresses distribution on a crosssection lead to formulae of questionable exactitude that sometimes overestimate the carrying capacity of the crosssection $[3,4]$.

The present work deals with the study of the interaction of the aforementioned internal forces and moments on a symmetrical I-section. The material is assumed elasticperfectly plastic. The warping stresses (due to non-uniform torsion) have been neglected due to the vagueness of the way and time of their appearance during the plasticization process of the cross-section [5]. Prandtl's theory of torsion, also known as Prandtl's membrane analogy, is used for the determination of the stresses caused by pure torsion (St. Venant's torsion) in the elastic as well as in the plastic regions $[6,7]$. A cross-section goes through certain stages of stressstate until its complete plasticization [8]. Decoupling of bending and torsional problems is based on the provisions of EC3.

The interaction formulae for internal forces and moments are determined for both the elastic and the plastic stage as well as for several partial plasticization stages of a crosssection using the above Prandtl's theory and the equivalence principle $[9,10]$.

*Address correspondence to this author at the Department of Civil Engineering, National Technical University of Athens, Athens 15780, Greece; Tel: +30 210 7723443; Fax: +3 2107722482 ;

E-mail: michalts@central.ntua.gr

\section{ELEMENTARY CONCEPTS}

\section{The Strains}

We consider the infinitesimal part $\mathrm{dx}$ of a beam which is strained by an axial force $\mathrm{N}_{\mathrm{x}}$ and a bending moment $\mathrm{M}_{\mathrm{y}}$. The beam is referred to the classic clockwise system of coordinates as it is shown in Figs. (1 and 2). On the plane of the neutral axis it is $\sigma_{\mathrm{x}}=0$ and therefore $\varepsilon_{\mathrm{x}}=0$.

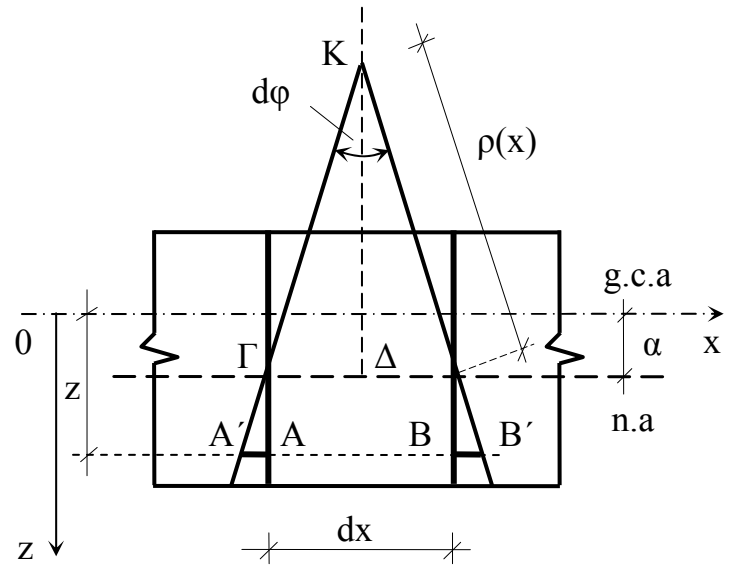

Fig. (1). Bending of an infinitesimal element dx.

Setting $\mathrm{dx}=\mathrm{AB}$, we can determine geometrically the normal strain from

$\varepsilon_{x}=\frac{\Delta d x}{d x}=\frac{A A^{\prime}+B B^{\prime}}{A B}=\frac{A A^{\prime}}{A B / 2}=\frac{A A^{\prime}}{\Gamma \Delta}$

and using the triangles $\Gamma \mathrm{A}^{\prime} \mathrm{A}$ and $\mathrm{K} \Gamma \Delta$ we have:

$\varepsilon_{x}=\frac{z-\alpha}{\rho(x)}$

where it is assumed

$\cos \frac{d \varphi}{2} \cong 1$. 


\section{The Stresses}

Let us consider next the cross-section in Fig. (2), which is symmetric about $\mathrm{Oz}$ axis. It is known that, when parts of the cross-section go into the plastic region, the neutral axis moves to its final position where equilibrium of forces and moments is satisfied.

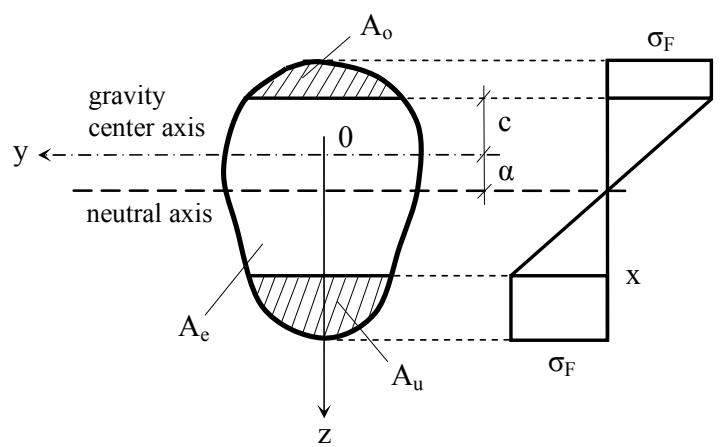

Fig. (2). Elastic-plastic stress distribution on a cross-sectional area A.

Easily, we find that:

$\frac{\sigma_{x}}{\sigma_{F}}=\frac{z+\alpha}{\alpha+c}$

If $\mathrm{A}_{\mathrm{o}}$ and $\mathrm{A}_{\mathrm{u}}$ are the top and bottom plastic regions of the cross-section $A$, and $A_{e}$ is the remaining elastic part, equilibrium of forces gives:

$\int_{A} \sigma_{x} d A=\int_{A_{e}} \sigma_{x} d A+\sigma_{F}\left(A_{u}-A_{o}\right)=N_{x}$

and finally

$\alpha \cdot A_{e}+\left(A_{u}-A_{o}-n_{x} \cdot A\right)(\alpha+c)=-S_{e}$

On the other hand, equilibrium of moments gives:

$\int_{A} \sigma_{x} z d A=\int_{A_{p}} \sigma_{F} z d A+\int_{A_{e}} \sigma_{F} \frac{z+\alpha}{\alpha+c} z d A=-M_{y}$

and finally

$\alpha \cdot S_{e}+\left(S_{o}-S_{u}-W_{y p} \cdot m_{y}\right)(\alpha+c)=-I_{e}$

where:

$n_{x}=\frac{N_{x}}{N_{x p}}, m_{y}=\frac{M_{y}}{M_{y p}}, S_{p o}=\int_{A_{o}} z d A$,

$S_{p u}=\int_{A_{u}} z d A, S_{e}=\int_{A_{e}} z d A, I_{e}=\int_{A_{e}} z^{2} d A$

and $\mathrm{W}_{\mathrm{yp}}$ is the resistant moment of the fully plastic crosssection. By solving the above system of eqs(3) and (4) we obtain the unknown quantities $\alpha$ and c.

\section{CLASSICAL THEORY OF PURE TORSION}

\section{The Principle}

For pure torsion, the shearing stresses $\tau_{\mathrm{xy}}$ and $\tau_{\mathrm{xz}}$ are independent on the normal ones $\sigma_{x}(y, z)$ [1]. In this case, we set: $\left.\begin{array}{l}u=u(x, y, z, D) \\ D=\varphi_{x}^{\prime}=\text { cons } \tan t\end{array}\right\}$

where $\varphi^{\prime}$ is the constant change of the rotation angle $\varphi$ of axis Ox. Using von Mises' criterion we have:

$\sigma_{x}^{2}+3 \cdot\left(\tau_{x y}^{2}+\tau_{x z}^{2}\right)=\sigma_{F}^{2}$

It is known that:

$\tau_{x y}=\frac{\partial \Phi}{\partial z}, \quad \tau_{x z}=-\frac{\partial \Phi}{\partial y}$

where $\Phi$, is the so called stress-function.

Introducing eqs(8) into eq(7), we finally obtain:

$\left(\frac{\partial \Phi}{\partial y}\right)^{2}+\left(\frac{\partial \Phi}{\partial z}\right)^{2}=\frac{1}{3}\left[\sigma_{F}^{2}-\sigma_{x}^{2}(y, z)\right]=F^{2}(y, z)$

with $\Phi=0$ on the boundaries, or finally:

$|\operatorname{grad} \Phi|=F(y, z)$, with $\Phi=0$ on $\mathrm{E}$

and

$F(y, z)=\frac{1}{\sqrt{3}} \cdot\left[\sigma_{F}^{2}-\sigma_{x}^{2}(y, z)\right]^{1 / 2}$

In order to solve the aformentioned boundary-value problem, we set:

$\left.\begin{array}{l}\tau_{x y}=\frac{\partial \Phi}{\partial z}=F(y, z) \cdot \cos \varphi(y, z) \\ \tau_{x z}=-\frac{\partial \Phi}{\partial y}=F(y, z) \cdot \sin \varphi(y, z)\end{array}\right\}$

The above stress distributions satisfy eqs(9). On the other hand it is known that:

$\frac{\partial \tau_{y x}}{\partial y}+\frac{\partial \tau_{z x}}{\partial z}=0$

and according to the Gauchy's principle:

$\frac{\partial \tau_{x y}}{\partial y}+\frac{\partial \tau_{x z}}{\partial z}=0$

Because of eqs(10), eq(11) becomes:

$\frac{\partial F}{\partial y} \cdot \cos \varphi-F \cdot \frac{\partial \varphi}{\partial y} \cdot \sin \varphi+\frac{\partial F}{\partial z} \cdot \sin \varphi+F \cdot \frac{\partial \varphi}{\partial z} \cdot \cos \varphi=0$

The following relations are valid (see Fig. 3):

$\left.\begin{array}{l}\frac{\partial \varphi}{\partial \eta}=\frac{\partial \varphi}{\partial y} \cdot \frac{\partial y}{\partial \eta}+\frac{\partial \varphi}{\partial z} \cdot \frac{\partial z}{\partial \eta}=-\frac{\partial \varphi}{\partial y} \cdot \sin \varphi+\frac{\partial z}{\partial \eta} \cdot \cos \varphi \\ \frac{\partial F}{\partial t}=\frac{\partial F}{\partial y} \cdot \frac{\partial y}{\partial t}+\frac{\partial F}{\partial z} \cdot \frac{\partial z}{\partial t}=\frac{\partial F}{\partial y} \cdot \cos \varphi+\frac{\partial F}{\partial z} \cdot \sin \varphi\end{array}\right\}$

Introducing eqs(13) into eq(12), we obtain:

$\frac{\partial \varphi}{\partial \eta}+\frac{1}{F} \cdot \frac{\partial F}{\partial t}=0$ 


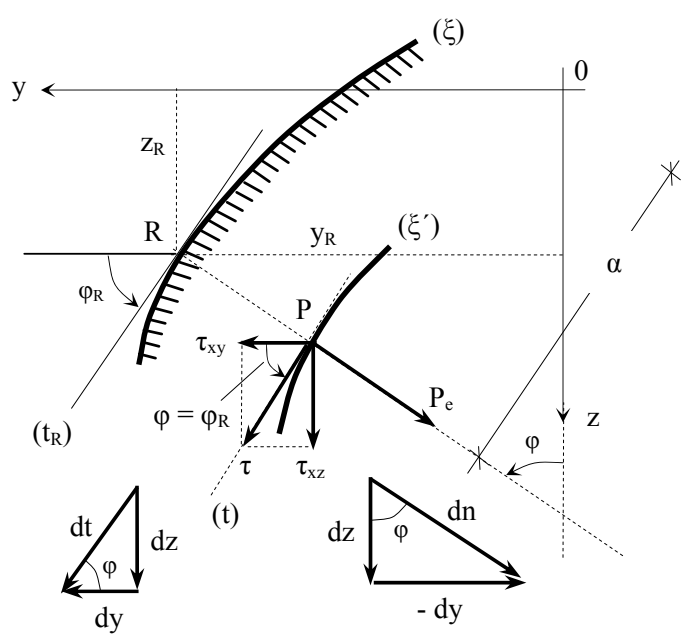

Fig. (3). Geometrical conditions of the shear stresses.

where $t$ and $\eta$ are the tangential and the normal directions, respectively, at point $\mathrm{R}\left(\mathrm{y}_{\mathrm{R}}, \mathrm{z}_{\mathrm{R}}\right)$ as shown in Fig. (3). Assuming that the equation of the boundary curve is known, i.e., that it has the form:

$$
f\left(\varphi_{R}\right)=z_{R}+y_{R} \cdot \cot \varphi_{R}
$$

we can integrate eq(14). Thus, the function $F$ can be determined and, subsequently, from eq(10) the stresses $\tau_{\mathrm{xy}}$ and $\tau_{\mathrm{xz}}$. Finally, the torsion moment $\mathrm{M}_{\mathrm{x}}$ can be determined using the well-known formula:

$$
M_{x}=2 G D \int_{A}\left(\tau_{x y} \cdot z+\tau_{x z} \cdot y\right) d A
$$

where $\mathrm{G}$ is the shear modulus of steel.

\section{The Case of a Symmetrical I-Cross-Section}

Depending on the stress state, $\sigma_{\mathrm{x}}$ may be either constant or variable along the main axes of the cross-section. In this work, we will examine the cases of constant or linearly varying normal stress $\sigma_{\mathrm{x}}$.

\section{The Stress $\sigma_{x}$ is Constant}

The main goal is to determine the additional torsion moment $\mathrm{M}_{\mathrm{x}}$ needed to fully plasticize a cross-section with area A subjected to a known axial force $\mathrm{N}_{\mathrm{x}}$. We symbolize with $\Phi_{\mathrm{p}}$ the stress function of the complete plasticization of $\mathrm{A}$ under the action of the $M_{x p}$ alone, and with $\Phi$ the one of the complete plasticization of $\mathrm{A}$ under the simultaneous action of $\mathrm{M}_{\mathrm{x}}$ and $\mathrm{N}_{\mathrm{x}}$.

According to the analysis presented in the previous paragraph, we can write:

$$
\left.\begin{array}{l}
\text { For } M_{x p}: \quad\left|\operatorname{grad} \Phi_{p}\right|=\frac{\sigma_{F}}{\sqrt{3}} \\
\text { For } N_{x}+M_{x}:|\operatorname{grad} \Phi|=\frac{1}{\sqrt{3}} \cdot\left[\sigma_{F}^{2}-\sigma_{x}^{2}\right]^{1 / 2}
\end{array}\right\}
$$

But since $\sigma_{x}=N_{x} / A=$ const., it also follows that $\sigma_{F}^{2}-\sigma_{x}^{2}=\sigma_{h}^{2}=$ const.. According to Prandtl's membrane theory, the membranes of eq(17), having constant inclinations, degenerate to simple roofs-in-plane with inclinations $|\operatorname{grad} \Phi|$ and $\left|\operatorname{grad} \Phi_{p}\right|$ as shown in Fig. (4). Therefore, the torsion moment $\mathrm{M}_{\mathrm{x}}$ (according to the above analysis) is equal to the double of the volume that is bounded by the membrane $\Phi$. Thus, one can write:

$$
\begin{aligned}
\frac{M_{x}}{M_{x p}}=\frac{\mathrm{Y}}{\mathrm{Y}_{p}}=\frac{\tan \vartheta}{\tan \vartheta_{p}} & =\frac{|\operatorname{grad} \Phi|}{\left|\operatorname{grad} \Phi_{p}\right|}= \\
& =\sqrt{1-\left(\frac{\sigma_{x}}{\sigma_{F}}\right)^{2}}=\sqrt{1-\left(\frac{N_{x}}{N_{x p}}\right)^{2}}
\end{aligned}
$$

or finally:

$$
n_{x}^{2}+m_{x}^{2}=1
$$

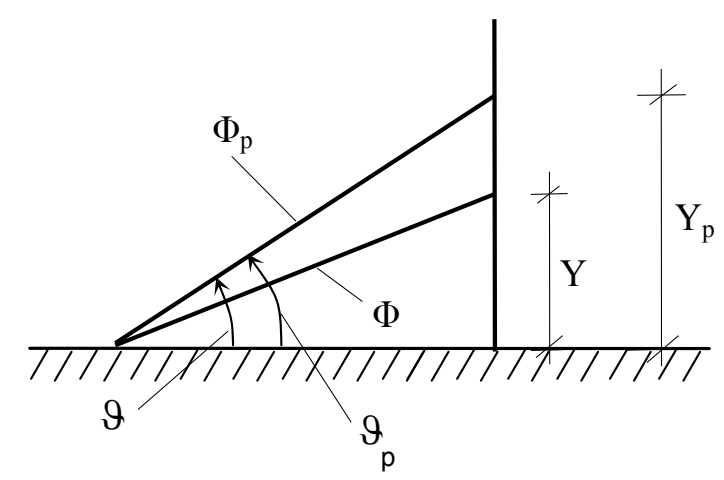

Fig. (4). Stress functions $\Phi$ and $\Phi_{P}$.

\section{The Stress $\sigma_{x}$ Varies Linearly}

In this case, we assume that the distribution of normal stresses $\sigma_{x}$ along the main axes of an orthogonal crosssection is known and we proceed to determine the torsion moment $M_{x}$, which along with the given external forces $N_{x}$ and $\mathrm{M}_{\mathrm{y}}\left(\right.$ or $\mathrm{N}_{\mathrm{x}}$ and $\mathrm{M}_{\mathrm{z}}$ ) causes the complete plasticization of the cross-section. In such a case, the stress $\sigma_{\mathrm{x}}$ varies linearly according to the following relation:

$$
\sigma_{x}=\frac{N_{x}}{A}+\frac{M_{y}}{W_{y}} \cdot \frac{z}{h / 2}
$$

Thus,

$\frac{\sigma_{x}}{\sigma_{F}}=\frac{N_{x} / A}{N_{x p} / A}+\frac{M_{y} / W_{y}}{M_{y p} / W_{y p}} \cdot \frac{z}{h / 2}=n_{x}+k_{y} \cdot m_{y} \cdot \frac{z}{h / 2}$

where

$n_{x}=\frac{N_{x}}{N_{x p}}, \quad m_{y}=\frac{M_{y}}{M_{y p}}, \quad k_{y}=\frac{W_{y p}}{W_{y}}$,

and $\mathrm{N}_{\mathrm{xp}}$ is the axial force which acting alone on the crosssection causes its complete plasticization, and $\mathbf{M}_{\mathrm{yp}}$ is the bending moment which acting alone causes the complete plasticization of the cross-section. Hence, eq(20) can be written as: 
$\frac{\sigma_{x}}{\sigma_{F}}=n_{x}+\frac{z}{\lambda}$, where $: \lambda=\frac{h}{2 \cdot k_{y} \cdot m_{y}}$

Equations (9a) and (9b) give:

$\left(\frac{\partial \Phi}{\partial y}\right)^{2}+\left(\frac{\partial \Phi}{\partial z}\right)^{2}=\frac{\sigma_{F}}{3} \cdot\left[1-\left(n_{x}+\frac{z}{\lambda}\right)^{2}\right]=F^{2}(z)$

with $\Phi=0$ on $\left(\mathrm{L}_{\mathrm{b}}\right)$.

In order to be able to determine the moment $M_{x}=2 V_{\Phi}$ through the calculation of the volume $\mathrm{V}_{\Phi}$ that is bounded below the membrane $\Phi(y, z)$, we must first solve the above boundary-value problem, as it is described by eq(22). For the solution of this problem, we apply eq(13b):

$\frac{\partial F}{\partial t}=\frac{\partial F}{\partial y} \cdot \cos \varphi+\frac{\partial F}{\partial z} \cdot \sin \varphi=-\frac{\sigma_{F}^{2}}{3} \cdot \frac{\lambda \cdot n_{x}+z}{\lambda^{2} \cdot F} \cdot \sin \varphi$

and eq(13a) becomes:

$$
\begin{aligned}
& \frac{\partial \varphi}{\partial \eta}=-\frac{1}{F} \cdot \frac{\partial F}{\partial t}=\frac{1}{F^{2}} \cdot\left(\frac{\sigma_{F}^{2}}{3} \cdot \frac{\lambda \cdot n_{x}+z}{\lambda^{2}}\right) \cdot \sin \varphi= \\
& =\frac{\frac{\lambda \cdot n_{x}+z}{\lambda^{2}}}{1-\left(\frac{\lambda \cdot n_{x}+z}{\lambda^{2}}\right)^{2}} \cdot \sin \varphi
\end{aligned}
$$

Since $d z=d \eta \cdot \cos \varphi$, the above equation can be written as follows:

$$
\frac{\partial \varphi}{\partial z} \cdot \cos \varphi=\frac{\lambda \cdot n_{x}+z}{\lambda^{2}-\left(\lambda \cdot n_{x}+z\right)^{2}} \cdot \sin \varphi
$$

or

$\cot \varphi \cdot d \varphi=\frac{\lambda \cdot n_{x}+z}{\lambda^{2}-\left(\lambda \cdot n_{x}+z\right)^{2}} \cdot d z=-\frac{d\left[\lambda^{2}-\left(\lambda \cdot n_{x}+z\right)^{2}\right]}{2 \cdot\left[\lambda^{2}-\left(\lambda \cdot n_{x}+z\right)^{2}\right]}$

or, in a more concise form

$\int \cot \varphi \cdot d \varphi=-\frac{1}{2} \cdot \int \frac{d\left[\lambda^{2}-\left(\lambda \cdot n_{x}+z\right)^{2}\right]}{\lambda^{2}-\left(\lambda \cdot n_{x}+z\right)^{2}}$

and

$$
\ln (\sin \varphi)=\ln \frac{c}{\sqrt{\lambda^{2}-\left(\lambda \cdot n_{x}+z\right)^{2}}}
$$

or, finally

$$
\sin \varphi=\frac{c}{\sqrt{\lambda^{2}-\left(\lambda \cdot n_{x}+z\right)^{2}}}
$$

For a random point $\mathrm{R}$ at the boundary $\alpha \beta$ (see Fig. 5), a value $\sin \varphi_{R}$ corresponds to each value of $z_{R}$, and hence, from eqs(23) we obtain:

$c=\sin \varphi_{R} \cdot \sqrt{\lambda^{2}-\left(\lambda \cdot n_{x}+z_{R}\right)^{2}}$

Thus, eq.(23) becomes:

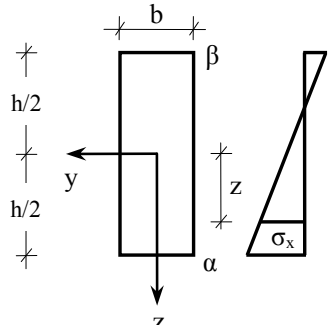

(a)

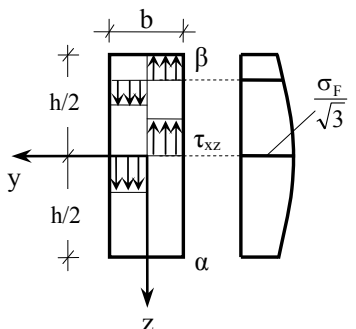

(b)
Fig. (5). (a) Distribution of normal stresses and (b) shear stresses.

$\sin \varphi=\sqrt{\frac{\lambda^{2}-\left(\lambda \cdot n_{x}+z_{R}\right)^{2}}{\lambda^{2}-\left(\lambda \cdot n_{x}+z\right)^{2}}} \cdot \sin \varphi_{R}$

Along the boundary $\alpha \beta$ (as shown in Fig. 5), it is $\sin \varphi_{R}=1$ and eq.(10) gives $\tau_{\mathrm{xz}}=\mathrm{F}(\mathrm{z}) \cdot \sin \varphi$, or:

$\tau_{x z}=\frac{\sigma_{F}}{\sqrt{3}} \cdot \sqrt{1-\left(\frac{\lambda \cdot n_{x}+z}{\lambda}\right)^{2}} \cdot \sqrt{\frac{\lambda^{2}-\left(\lambda \cdot n_{x}+z_{R}\right)^{2}}{\lambda^{2}-\left(\lambda \cdot n_{x}+z\right)^{2}}}$

and

$\tau_{x z}=\frac{\sigma_{F}}{\sqrt{3}} \cdot \sqrt{\frac{\lambda^{2}-\left(\lambda \cdot n_{x}+z_{R}\right)^{2}}{\lambda^{2}}}$

where $z_{R}$ is now equal to $z$, because it expresses the ordinate of the boundary $\alpha \beta$. So, eqs $(25)$ give for $z_{R}=z$ the diagram of Fig. (5b), while the additional torsion moment $\mathrm{M}_{\mathrm{x}}$ will be:

$$
\begin{aligned}
& M_{x}=\int_{-h / 2}^{h / 2} \tau_{x z}\left(\frac{b}{2}\right)^{2} d z=\frac{\sigma_{F} \cdot b^{2}}{4 \cdot \sqrt{3}} \cdot \int_{-h / 2}^{h / 2} \sqrt{1-\left(\frac{\lambda \cdot n_{x}+z}{\lambda}\right)^{2}} \cdot d z= \\
& =\frac{\sigma_{F} \cdot b^{2}}{4 \cdot \sqrt{3}} \cdot \lambda \int_{-h / 2}^{h / 2} \sqrt{1-\left(\frac{\lambda \cdot n_{x}+z}{\lambda}\right)^{2}} \cdot d\left(\frac{\lambda \cdot n_{x}+z}{\lambda}\right)= \\
& =\frac{\sigma_{F} \cdot b^{2}}{4 \cdot \sqrt{3}} \cdot \frac{\lambda}{2} \cdot\left[\frac{\lambda \cdot n_{x}+z}{\lambda} \cdot \sqrt{1-\left(\frac{\lambda \cdot n_{x}+z}{\lambda}\right)^{2}}+\arcsin \left(\frac{\lambda \cdot n_{x}+z}{\lambda}\right)\right]_{-h / 2}^{h / 2}
\end{aligned}
$$

or finally:

$$
\begin{aligned}
& M_{x}=\frac{\sigma_{F} b^{2} \lambda}{8 \cdot \sqrt{3}}\left[\left(n_{x}+\frac{h}{2 \lambda}\right) \sqrt{1-\left(n_{x}+\frac{h}{2 \lambda}\right)^{2}}-\right. \\
& -\left(n_{x}-\frac{h}{2 \lambda}\right) \sqrt{1-\left(n_{x}-\frac{h}{2 \lambda}\right)^{2}}+ \\
& \left.+\arcsin \left(n_{x}+\frac{h}{2 \lambda}\right)-\arcsin \left(n_{x}-\frac{h}{2 \lambda}\right)\right]
\end{aligned}
$$

Introducing the expression of $\lambda$ from eq(21b) into the above expression, we obtain:

$$
\begin{gathered}
\frac{M_{x}}{\sigma_{F}}=\frac{M_{x}}{M_{x p} / J_{d p}}=\frac{b^{2} \lambda h}{16 k_{y} m_{y} \sqrt{3}}\left[\left(n_{x}+k_{y} m_{y}\right) \sqrt{1-\left(n_{x}+k_{y} m_{y}\right)^{2}}\right. \\
-\left(n_{x}-k_{y} m_{y}\right) \sqrt{1-\left(n_{x}-k_{y} m_{y}\right)^{2}}+ \\
\left.+\arcsin \left(n_{x}+k_{y} m_{y}\right)-\arcsin \left(n_{x}-k_{y} m_{y}\right)\right]
\end{gathered}
$$

and finally: 


$$
\begin{aligned}
m_{x}=\frac{1}{J_{d p}} \cdot \frac{b^{2} \lambda h}{16 k_{y} m_{y} \sqrt{3}}\left[\left(n_{x}+k_{y} m_{y}\right) \sqrt{\left(n_{x}+k_{y} m_{y}\right)}-\right. \\
-\left(n_{x}-k_{y} m_{y}\right) \sqrt{\left(n_{x}-k_{y} m_{y}\right)} \\
\left.+\arcsin \left(n_{x}+k_{y} m_{y}\right)-\arcsin \left(n_{x}-k_{y} m_{y}\right)\right]
\end{aligned}
$$

where $\mathrm{J}_{\mathrm{dp}}$ for an orthogonal cross-section is given by

$$
J_{d p}=\frac{h b^{2}}{4 \sqrt{3}} .
$$

\section{INTERACTION CURVES}

Since the methodology presented in the previous paragraph is too extensive, we will examine in detail only a limited number of cases that are the most characteristic ones. This technique can be applied to all other cases.

\section{The Case $\mathbf{N}_{\mathbf{x}}+\mathrm{M}_{\mathrm{x}}$}

This case is already presented above. If $\mathrm{N}_{\mathrm{x}}$ is the acting axial force and $\mathrm{M}_{\mathrm{x}}$ the searched additional torsion moment, the following relation is valid:

$n_{x}^{2}+m_{x}^{2}=1$

where $\mathrm{n}_{\mathrm{x}}=\mathrm{N}_{\mathrm{x}} / \mathrm{N}_{\mathrm{xp}}$ and $\mathrm{m}_{\mathrm{x}}=\mathrm{M}_{\mathrm{x}} / \mathrm{M}_{\mathrm{xp}}$.

\section{The Case $M_{x}+M_{y}$}

We assume that the distribution of the stresses, caused by a bending moment $\mathrm{M}_{\mathrm{y}}$, along the $\mathrm{Oz}$ axis is known (see Fig. 6). If $\mathrm{A}$ is the area of a doubly symmetric I-cross-section, we search for the additional torsion moment $M_{x}$ which acting simultaneously with the given bending moment $\mathrm{M}_{\mathrm{y}}$ causes the complete plasticization of the cross-section A. The crosssection goes to its complete plasticization through the following steps:

\section{$1^{\text {st }}$ Step}

This step starts from $M_{y}=0$ up to the plasticization of the first external fiber under the moment $M_{y 1}$. It is $M_{y 1}=\sigma_{F} \cdot W_{y}$, or finally:

$m_{y 1}=\frac{M_{y 1}}{M_{y p}}=\frac{W_{y}}{W_{y p}}$

$$
2^{\text {nd }} \text { Step }
$$

This step starts from $M_{\mathrm{y} 1}$ up to the plasticization of both flanges under the moment $\mathrm{M}_{\mathrm{y} 2}$. It is
$M_{y 2}=M_{y p}-2 \cdot \frac{1}{2} \cdot \sigma_{F} t_{w} \frac{h_{o}^{2}}{3}$,

or finally:

$m_{y 2}=\frac{M_{y 2}}{M_{y p}}=1-\frac{h_{o} A_{w}}{6 W_{y p}}$

$3^{\text {rd }}$ Step

This step starts from $\mathrm{M}_{\mathrm{y} 2}$ up to the complete plasticization of the entire cross-section under the moment $\mathrm{M}_{\mathrm{yp}}$.

\section{The $1^{\text {st }}$ Step: Torsion on the Entire Cross-Section}

\section{The Part I (Flanges)}

In this case, since it is $t_{f}<<h$, and the direction of shear stresses $\tau$ is parallel to the flanges' large dimension, one can consider the mean stress of each flange (see also Fig. 6). It is:

$$
\frac{\sigma_{o}}{\sigma_{F}}=\frac{M_{y} / W_{y}}{M_{y p} / W_{y p}}=k_{y} \cdot m_{y}
$$

where $\mathrm{k}_{\mathrm{y}}$ can be obtained from eq(20). Thus:

$$
\frac{\sigma_{m}}{\sigma_{F}}=k_{y} \cdot m_{y} \cdot \frac{h+2 h_{o}}{2 h}
$$

and from eq(18a) we have:

$$
\frac{M_{x I}}{M_{x I p}}=\frac{|\operatorname{grad} \Phi|}{\left|\operatorname{grad} \Phi_{p}\right|}=\frac{\frac{1}{\sqrt{3}} \sqrt{\sigma_{F}^{2}+\sigma_{m}^{2}}}{\sigma_{F} / \sqrt{3}}=\sqrt{1-\left(\frac{\sigma_{m}}{\sigma_{F}}\right)^{2}}
$$

or

$$
M_{x I}=\sigma_{F} \cdot J_{d p I} \sqrt{1-k_{y}^{2}\left(\frac{h+2 h_{o}}{2 h}\right)^{2} m_{y}^{2}}
$$

where

$$
J_{d p I}=\frac{b \cdot t_{f}^{2}}{2 \cdot \sqrt{3}}
$$

for both flanges.

\section{The Part II (Web)}

It is (see Fig. 6):

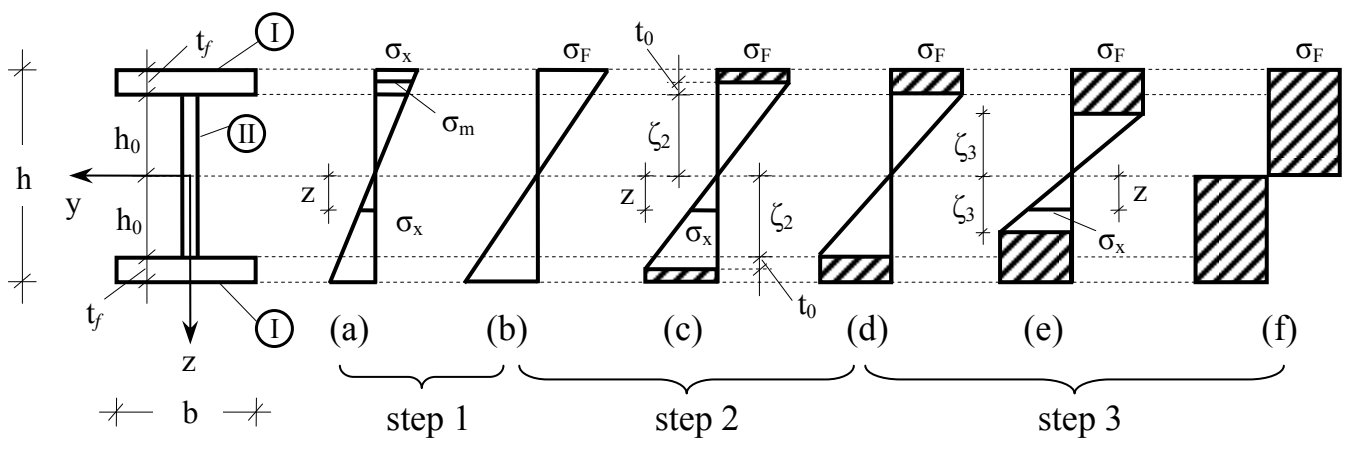

Fig. (6). Normal stresses on an I-section during the plasticization progress. 
$\frac{\sigma_{x}}{\sigma_{F}}=\frac{\sigma_{o}}{\sigma_{F}} \cdot \frac{z}{h / 2}=\frac{z}{\lambda}$

where

$\lambda=\frac{h}{2 \cdot k_{y} \cdot m_{y}}$

With $\mathrm{n}_{\mathrm{x}}=0$ and $\lambda$ computed from eq(32), eq(26a) gives:

$$
\begin{aligned}
M_{x I I}=\frac{\sigma_{F} t_{w}^{2}}{4 \sqrt{3}}\left[h_{o} \sqrt{1-\left(\frac{2 h_{o} k_{y}}{h} m_{y}\right)^{2}}+\right. \\
\left.+\frac{h}{2 k_{y} m_{y}} \arcsin \left(\frac{2 h_{o} k_{y}}{h} m_{y}\right)\right]
\end{aligned}
$$

Thus, the total torsion moment is the summation of the above two parts $\mathrm{M}_{\mathrm{xI}}$ and $\mathrm{M}_{\mathrm{xII}}$ :

$$
\begin{aligned}
& M_{x}=\sigma_{F} J_{d p I} \sqrt{1-k_{y}^{2}\left(\frac{h+\rho_{y}}{2}\right)^{2} m_{y}^{2}}+ \\
& +\frac{\sigma_{F} t_{w}^{2}}{4 \sqrt{3}}\left[h_{o} \sqrt{1-\rho_{y}^{2} m_{y}^{2}}+\frac{h}{2 k_{y} m_{y}} \arcsin \left(\rho_{y} m_{y}\right)\right]
\end{aligned}
$$

and finally:

$$
\begin{aligned}
& m_{x 1}=\frac{1}{J_{d p}}\left\{J_{d p I} \sqrt{1-k_{y}^{2}\left(\frac{h+\rho_{y}}{2}\right)^{2} m_{y}^{2}}+\right. \\
& \left.+\frac{t_{w}^{2}}{4 \sqrt{3}}\left[h_{o} \sqrt{1-\rho_{y}^{2} m_{y}^{2}}+\frac{h}{2 k_{y} m_{y}} \arcsin \left(\rho_{y} m_{y}\right)\right]\right\}
\end{aligned}
$$

with $k_{y}=W_{y p} / W_{y}$ and $\rho_{y}=2 h_{o} k_{y} / h$.

The $2^{\text {nd }}$ Step: Torsion on the Web and a Part of Flanges $\left(\mathbf{h}_{\mathbf{0}}<\zeta<\mathbf{h} / 2\right)$

Since an exact calculation of distance $\zeta_{2}$ (Fig. 6c) leads to the solution of a $3^{\text {rd }}$ order algebraic equation and observing that $\zeta_{2}$ varies almost linearly within thickness $t_{f}$, one can determine $\zeta_{2}$ through the following approximate relation:

$\zeta_{2}=\frac{h}{2}-\frac{6 \cdot t_{f} \cdot\left(W_{y}-W_{y p} \cdot m_{y}\right)}{6 \cdot\left(W_{y}-W_{y p}\right)+h_{o} \cdot A_{w}}$

We divide the elastic region of the cross-section in two parts: the elastic part of the flanges and elastic part of the web (as shown in Fig. 6c).

\section{The Part I (Flanges)}

Since the thickness $t_{f}$ of the flanges is small compared to the height $h$, one can consider that the normal stresses in Fig. (6c) have a uniform distribution along the thickness $t_{0}$. So, one can use the mean stress:

$\sigma_{m}=\frac{\sigma_{F}+\sigma_{x}\left(h_{o}\right)}{2}=\sigma_{F} \cdot \frac{h_{o}+\zeta_{2}}{2 \cdot \zeta_{2}}$

Using eq(19a), we obtain the following relation:
$M_{x I}=\sigma_{F} \cdot J_{d p I} \cdot \sqrt{1-\left(\frac{h_{o}+\zeta_{2}}{2 \zeta_{2}}\right)^{2}}$

where

$$
J_{d p I}=\frac{b \cdot t_{o}^{2}}{2 \sqrt{3}}=\frac{b \cdot\left(\zeta_{2}-h_{o}\right)^{2}}{2 \sqrt{3}}
$$

\section{The Part II (Web)}

The normal stress $\sigma_{\mathrm{x}}$ at a distance $\mathrm{z}$ (Fig. 6c) is given by:

$$
\sigma_{x}(z)=\sigma_{F} \cdot \frac{z}{\zeta_{2}}
$$

that has the same form with the expression of eq(32). Following the same procedure as the one presented above, one can obtain the relation:

$$
\tau_{x z}=\frac{\sigma_{F}}{\sqrt{3}} \sqrt{\frac{\zeta_{2}^{2}-z^{2}}{\zeta_{2}^{2}}} \text { for }-h_{o} \leq z \leq h_{o}
$$

The torsion moment undertaken by part II will be:

$$
\begin{aligned}
M_{x I I}= & \int_{-h_{o}}^{h_{o}} \tau_{x z}\left(\frac{t_{w}}{2}\right)^{2} d z=\frac{\sigma_{F}}{4 \sqrt{3}} \cdot t_{w}^{2} \cdot \zeta_{2} . \\
& \cdot \frac{1}{2} \cdot\left[\frac{z}{\zeta_{2}} \cdot \sqrt{1-\left(\frac{z}{\zeta_{2}}\right)^{2}}+\arcsin \frac{z}{\zeta_{2}}\right]_{-h_{o}}^{h_{o}}
\end{aligned}
$$

or finally

$$
M_{x I I}=\frac{\sigma_{F} \cdot t_{w}^{2}}{4 \sqrt{3}} \cdot \zeta_{2} \cdot\left[\frac{h_{o}}{\zeta_{2}} \cdot \sqrt{1-\left(\frac{h_{o}}{\zeta_{2}}\right)^{2}}+\arcsin \frac{h_{o}}{\zeta_{2}}\right]
$$

Thus, the total torsion moment is the sum of the above two parts $\mathrm{M}_{\mathrm{xI}}$ and $\mathrm{M}_{\mathrm{xII}}$ :

$$
\begin{aligned}
& M_{x}=\sigma_{F} \cdot \frac{b \cdot\left(\zeta_{2}-h_{o}\right)^{2}}{2 \sqrt{3}} \cdot \sqrt{1-\left(\frac{h_{o}+\zeta_{2}}{2 \zeta_{2}}\right)^{2}}+ \\
& +\frac{\sigma_{F} \cdot t_{w}^{2}}{4 \sqrt{3}} \cdot\left[h_{o} \cdot \sqrt{1-\left(\frac{h_{o}}{\zeta_{2}}\right)^{2}}+\zeta_{2} \cdot \arcsin \frac{h_{o}}{\zeta_{2}}\right]
\end{aligned}
$$

and finally:

$$
m_{x}=\frac{1}{J_{d p}} \cdot\left\{\begin{array}{l}
\frac{b \cdot\left(\zeta_{2}-h_{o}\right)^{2}}{2 \sqrt{3}} \cdot \sqrt{1-\left(\frac{h_{o}+\zeta_{2}}{2 \zeta_{2}}\right)^{2}}+ \\
+\frac{t_{w}^{2}}{4 \sqrt{3}} \cdot\left[h_{o} \cdot \sqrt{1-\left(\frac{h_{o}}{\zeta_{2}}\right)^{2}}+\zeta_{2} \cdot \arcsin \frac{h_{o}}{\zeta_{2}}\right]
\end{array}\right\}
$$

where $\zeta_{2}$ can be computed from eq(35).

\section{The $3^{\text {rd }}$ Step: Torsion Only on the Web $\left(\zeta_{3}<h_{0}\right)$}

In this case (see Fig. 6e), we have:

$$
M_{y}=M_{y p}-t_{w} \cdot \sigma_{F} \cdot \zeta_{3}^{2} / 3
$$

or finally: 
$\zeta_{3}=\sqrt{\frac{3 W_{y p}}{t_{w}} \cdot\left(1-m_{y}\right)}$

On the other hand, we know that (see Fig. 6e):

$\sigma_{x}(z)=\sigma_{F} \cdot \frac{z}{\zeta_{3}} \quad$ for $\quad|z| \leq \zeta_{3}$

The above expression has the same form with eq(38). Following the same procedure as the one presented above, we obtain the expression:

$\tau_{x z}=\frac{\sigma_{F}}{\sqrt{3}} \sqrt{\frac{\zeta_{3}^{2}-z^{2}}{\zeta_{3}^{2}}}$ for $-\zeta_{3} \leq z \leq \zeta_{3}$

The torsion moment will be:

$M_{x}=\frac{\sigma_{F}}{4 \sqrt{3}} \cdot t_{w}^{2} \frac{\zeta_{3}}{2}\left[\frac{z}{\zeta_{3}} \cdot \sqrt{1-\left(\frac{z}{\zeta_{3}}\right)^{2}}+\arcsin \frac{z}{\zeta_{3}}\right]_{-\zeta_{3}}^{\zeta_{3}}=$

$=\frac{\sigma_{F} \cdot t_{w}^{2} \cdot \pi}{8 \sqrt{3}} \cdot \zeta_{3}$

or finally

$m_{x}=\frac{\pi \cdot t_{w}^{2}}{8 \sqrt{3} \cdot J_{d p}} \cdot \sqrt{\frac{3 W_{y p}}{t_{w}} \cdot\left(1-m_{y}\right)}$

\section{The Case $M_{x}+M_{z}$}

Following the procedure given in the previous paragraph, one can distinguish between the following two cases (see Fig. 7):

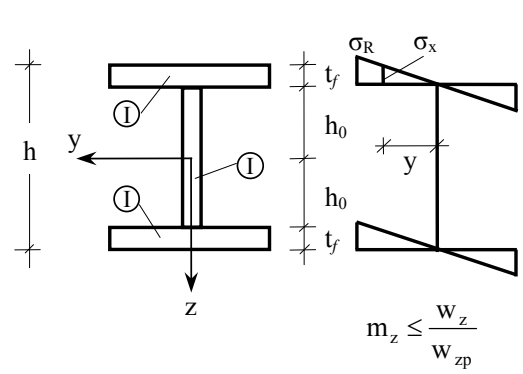

(a)

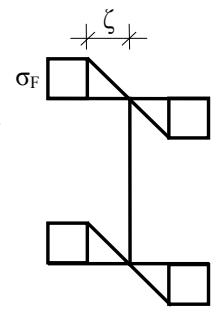

$\mathrm{m}_{\mathrm{z}} \geq \frac{\mathrm{w}_{\mathrm{z}}}{\mathrm{w}_{\mathrm{zp}}}$

(b)
Fig. (7). Normal stress $\sigma_{\mathrm{x}}$ for bending moment $\mathrm{M}_{\mathrm{z}}$.

\section{Torsion on the Entire Cross-Section}

Neglecting the very small part of bending moment $M_{z}$ that can be undertaken by the web and assuming that the flanges undertake the whole bending moment $\mathrm{M}_{\mathrm{z}}$, we have:

$\frac{\sigma_{R}}{\sigma_{F}}=\frac{M_{z} / W_{z}}{M_{z p} / W_{z p}}=k_{z} \cdot m_{z}$

and
$\frac{\sigma_{x}}{\sigma_{R}}=\frac{y}{b / 2}$

thus $\sigma_{x}=\sigma_{R} \cdot 2 y / b=\sigma_{F} \cdot k_{z} \cdot m_{z} \cdot 2 y / b$, or finally:

$\frac{\sigma_{x}}{\sigma_{F}}=\frac{y}{\lambda}, \quad$ where $: \lambda=\frac{b}{2 \cdot k_{z} \cdot m_{z}}$

For the flanges, it is valid that

$\left(\frac{\partial \Phi}{\partial y}\right)^{2}+\left(\frac{\partial \Phi}{\partial z}\right)^{2}=\frac{\sigma_{F}}{\sqrt{3}} \cdot\left[1-\left(\frac{y}{\lambda}\right)^{2}\right]$

and, therefore,

$$
\begin{aligned}
& M_{x I}=2 \int_{-b / 2}^{b / 2} \frac{\sigma_{F} \cdot t_{f}^{2}}{4 \sqrt{3}} \cdot \sqrt{1-\left(\frac{y}{\lambda}\right)^{2}} d y= \\
& =2 \cdot \frac{\sigma_{F} \cdot t_{f}^{2}}{4 \sqrt{3}} \cdot \frac{\lambda}{2} \cdot\left[\frac{y}{\lambda} \cdot \sqrt{1-\left(\frac{y}{\lambda}\right)^{2}}+\arcsin \frac{y}{\lambda}\right]_{-b / 2}^{b / 2} \\
& =2 \cdot \frac{\sigma_{F} \cdot t_{f}^{2}}{4 \sqrt{3}} \cdot\left[\frac{\frac{b}{2} \cdot \sqrt{1-\left(k_{z} \cdot m_{z}\right)^{2}}+}{+\frac{b}{2 \cdot k_{z} \cdot m_{z}} \cdot \arcsin \left(k_{z} \cdot m_{z}\right)}\right]
\end{aligned}
$$

On the other hand, normal stresses do not develop within the web due to the axial force but only shear stresses due to torsion. Thus,

$M_{x I I}=\sigma_{F} \cdot J_{d p I I}$

The total torsion moment is the summation of the above two parts $\mathrm{M}_{\mathrm{xI}}$ and $\mathrm{M}_{\mathrm{xII}}$ :

$$
\begin{aligned}
& m_{x}=\frac{1}{J_{d p}} \cdot\left\{J_{d p I I}+\frac{t_{f}^{2}}{2 \sqrt{3}} \cdot\left[\frac{b}{2} \cdot \sqrt{1-\left(k_{z} \cdot m_{z}\right)^{2}}+\right.\right. \\
& \left.\left.+\frac{b}{2 \cdot k_{z} \cdot m_{z}} \cdot \arcsin \left(k_{z} \cdot m_{z}\right)\right]\right\}
\end{aligned}
$$

where

$J_{d p I I}=\frac{h_{o} \cdot t_{w}^{2}}{2 \sqrt{3}}$.

\section{Torsion on the Web and a Part of Flanges}

This case exists only if

$m_{z} \geq W_{z} / W_{z p}$

Then, the following relation is valid:

$M_{z}=M_{z p}-\sigma_{F} \cdot t_{f} \cdot 2 \cdot \zeta^{2} / 3$

or finally:

$\zeta=\sqrt{\frac{3 W_{z p}}{2 t_{f}} \cdot\left(1-m_{z}\right)}$

and through an analysis analogous to the one presented above, we obtain: 
$M_{x I}=2 \cdot \frac{\sigma_{F} \cdot t_{f}^{2} \cdot \pi}{8 \sqrt{3}} \cdot \zeta$

Thus, the total torsion moment is the summation of the above two parts $\mathrm{M}_{\mathrm{xI}}$ and $\mathrm{M}_{\mathrm{xII}}$, with $\mathrm{M}_{\mathrm{xII}}$ computed from eq(47)

$m_{x}=\frac{1}{J_{d p}} \cdot\left[J_{d p I I}+\frac{\pi \cdot t_{f}^{2}}{4 \sqrt{3}} \cdot \sqrt{\frac{3 \cdot W_{z p}}{2 \cdot t_{f}} \cdot\left(1-m_{z}\right)}\right]$

The Case $M_{x}+M_{y}+V_{z}$

In the present case (existence of $\mathrm{M}_{\mathrm{y}}$ and $\mathrm{V}_{\mathrm{z}}$ ) and since the flanges undertake an almost negligible part of the shear force $(\sim 2 \%)$, we can assume that the shear force is undertaken solely by the web. The shear force $V_{z p}$ (i.e., the shear force needed for complete plasticization of the cross-section) will be:

$V_{z p}=A_{w} \cdot \sigma_{F} / \sqrt{3}=2 \cdot h_{o} \cdot t_{w} \cdot \sigma_{F} / \sqrt{3}$

\section{Torsion on the Entire Cross-Section}

The stresses $\sigma_{\mathrm{x}}$ and $\tau$ are given by the following expressions:

$\sigma_{x}=\frac{M_{y}}{J_{y}} \cdot z, \quad \tau=\frac{V_{z}}{J_{y} \cdot t_{w}}\left[\frac{A_{f}}{4}\left(h-t_{f}\right)+t_{w} \frac{h_{o}^{2}-z^{2}}{2}\right]$

The most unfavorable stress combination occurs at $\mathrm{z}=(\mathrm{h}-$ $2 \mathrm{t}_{\mathrm{f}} / 2$, and since

$\sigma_{h}=\sigma_{F}=\sqrt{\sigma_{x}^{2}+3 \tau^{2}}$

the following condition must be also valid in order for the cross-section to be able to undertake an additional torsion moment:

$V_{z}^{2} \leq \frac{16 \cdot t_{w}^{2}}{A_{f}^{2}\left(h-t_{f}\right)^{2}} \cdot\left[\frac{\sigma_{F}^{2} \cdot J^{2}}{3}-\left(\frac{h-2 \cdot t_{f}}{2}\right)^{2} \cdot M_{y}^{2}\right]$

The distribution of shear stresses in a rectangular crosssection due to simultaneous action of torsion moment $\mathrm{M}_{\mathrm{x}}$ and shear force $\mathrm{V}_{\mathrm{z}}$ may be regarded similarly to the distribution of normal stresses caused by axial force $\mathrm{N}_{\mathrm{x}}$ and bending moment $\mathrm{M}_{\mathrm{y}}$. Thus, we consider the model shown in Fig. (8), where $t_{V}$ is the width of the web that can be plasticized by the shear force $V_{z}$.
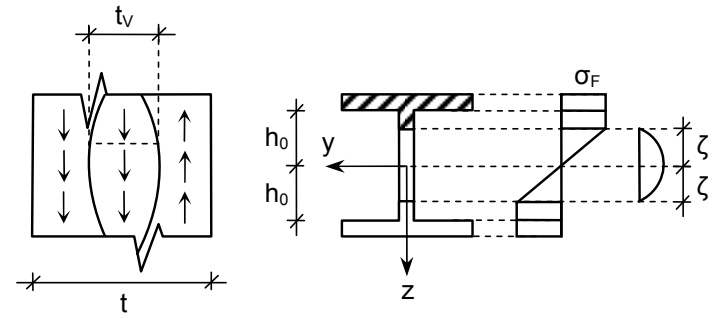

Fig. (8). Shear stress distribution in the web.

In this case, the following relation is valid

$t_{V} \cdot \frac{\sigma_{F}}{\sqrt{3}} \cdot d z=t_{w} \cdot \tau \cdot d z$ and taking into account the second expression of eq(54), the above relation results $t_{\mathrm{V}}=\mu(\mathrm{z}) \cdot \mathrm{v}$, where $\mathrm{v}=\mathrm{V}_{\mathrm{z}} / \mathrm{V}_{\mathrm{zp}}$ and

$\mu(z)=\frac{A}{J_{y}} \cdot\left[\frac{A_{f}}{4} \cdot\left(h-t_{f}\right)+t_{w} \cdot \frac{h_{o}^{2}-z^{2}}{2}\right]$

Thus, the searched torsion moment of the web will be

$M_{x I I}=\int_{-h_{o}}^{h_{o}} \tau_{x z} \cdot \frac{t_{w}^{2}-t_{v}^{2}}{4} d z$

and

$$
\begin{aligned}
& m_{x}=\frac{1}{J_{d p}} \cdot\left\{J_{d p I} \cdot \sqrt{1-\left(\frac{k_{y}+\rho_{y}}{2}\right)^{2} \cdot m_{y}^{2}}+\right. \\
& +\frac{t_{w}^{2}}{4 \sqrt{3}}\left[h_{o} \sqrt{1-\rho_{y}^{2} \cdot m_{y}^{2}}+\frac{h}{2 k_{y} m_{y}} \cdot \arcsin \left(\rho_{y} m_{y}\right)\right]- \\
& \left.-v^{2} \cdot \int_{-h_{o}}^{h_{o}} \frac{\left(\rho_{1}-\rho_{2} \cdot z^{2}\right)^{2}}{4 \cdot \sqrt{3}} \sqrt{1-\left(\frac{z}{\lambda}\right)^{2}} \cdot d z\right\} \\
& \text { with: } k_{y}=W_{y p} / W_{y}, \quad \rho_{y}=2 h_{o} \cdot k_{y} / h
\end{aligned}
$$

\section{Torsion on the Web and a Part of Flanges}

The distribution of shear stresses $\tau$ is the shown in Fig. (8). Under the same assumptions eq(36) is valid, and thus we finally obtain:

$$
\begin{aligned}
& m_{x}=\frac{1}{J_{d p}} \cdot\left\{\frac{b \cdot\left(\zeta-h_{o}\right)^{2}}{2 \sqrt{3}} \cdot \sqrt{1-\left(\frac{h_{o}+\zeta}{2 \zeta}\right)^{2}}+\right. \\
& +\frac{t_{w}^{2}}{4 \sqrt{3}} \cdot\left[h_{o} \cdot \sqrt{1-\left(\frac{h_{o}}{\zeta}\right)^{2}}+\zeta \cdot \arcsin \frac{h_{o}}{\zeta}\right]- \\
& -v^{2} \cdot \int_{-h_{o}}^{h_{o}} \frac{\left(\rho_{1}-\rho_{2} \cdot z^{2}\right)^{2}}{4 \cdot \sqrt{3}} \sqrt{1-\left(\frac{z}{\lambda}\right)^{2}} \cdot d z
\end{aligned}
$$

\section{Torsion Only on the Web}

It can be easily proved that the distribution of shear stresses starts from the boundaries of the plastic regions of the cross-section, as shown in Fig. (7b). Thus the part of the web that receives the shear stresses due to $\mathrm{V}_{\mathrm{z}}$, may as well behave like a rectangular cross-section with dimensions $2 \cdot \zeta \cdot \mathrm{t}_{\mathrm{w}} \cdot$ Evidently, we may write:

$$
\sigma_{x}=\sigma_{F} \cdot \frac{z}{\zeta}, \quad \tau=\frac{3 \cdot V_{z}}{4 \cdot t_{w}} \cdot \frac{1}{\zeta} \cdot\left[1-\left(\frac{z}{\zeta}\right)^{2}\right]
$$

and

$$
\tau_{\max }=\frac{3 \cdot V_{z}}{4 \cdot \zeta \cdot t_{w}}
$$

When $\tau_{\max }$ reaches the limit value $\tau_{F}=\sigma_{F} / \sqrt{3}$, eq $(8 \mathrm{c})$ gives:

$\zeta=\frac{3 \cdot \sqrt{3} \cdot V_{z}}{4 \cdot t_{w} \cdot \sigma_{F}}$ 
According to the diagram in Fig. (7a), one can write $M_{y}=M_{y p}-\sigma_{F} \cdot t_{w} \cdot \zeta^{2} / 3$, or because of eq(40) and taking into account eq(33), we find that in order for the crosssection to be able to undertake a torsion moment $\mathrm{M}_{\mathrm{x}}$ the following condition must apply:

$V_{z}^{2} \leq \frac{16}{9} \cdot \frac{t_{w} \cdot W_{p}}{A_{w}^{2}} \cdot\left(1-\frac{M_{y}}{M_{y p}}\right) \cdot V_{z p}^{2}$

The width $t_{v}$, using eq(39b), is:

$t_{v}=\frac{3 \cdot \sqrt{3}}{4 \cdot t_{w} \cdot \zeta \cdot \sigma_{F}}\left[1-\left(\frac{z}{\zeta}\right)^{2}\right]=$
$=\frac{3 \cdot h_{o}}{2 \cdot \zeta} \cdot\left[1-\left(\frac{z}{\zeta}\right)^{2}\right] \cdot \frac{V_{z}}{V_{z p}}$

and, the searched torsion moment will be:

$$
\begin{aligned}
& m_{x}=\frac{\pi \cdot t_{w}^{2}}{8 \sqrt{3} \cdot J_{d p}} \cdot \sqrt{\frac{3 \cdot W_{y p}}{t_{w}} \cdot\left(1-m_{y}\right)}- \\
& -\frac{1}{J_{d p}} \cdot v^{2} \cdot \int_{-\zeta}^{\zeta} \frac{\sqrt{3} \cdot h_{o}}{2 \cdot \zeta} \cdot\left[1-\left(\frac{z}{\zeta}\right)^{2}\right]^{2} \sqrt{1-\left(\frac{z}{\zeta}\right)^{2}} \cdot d z
\end{aligned}
$$

\section{The Special Case $M_{x}+V_{z}$}

Following the same procedure as in the previous section, we obtain:

$$
m_{x}=1-\frac{1}{4 J_{d p} \sqrt{3}} \cdot v^{2} \cdot \int_{-h_{o}}^{h_{o}} \mu(z) \cdot \sqrt{1-\left(\frac{z}{h_{o}}\right)^{2}} d z
$$

for $\mathrm{V}_{\mathrm{z}} \leq \mathrm{A}_{\mathrm{w}} / \mathrm{A}$, and

$$
\begin{aligned}
& m_{x}=1-\frac{\left(A \cdot v-A_{w}\right)^{2}}{8 \cdot b \cdot J_{d p} \sqrt{3}}- \\
& -\frac{1}{4 J_{d p} \sqrt{3}} \cdot\left(\frac{A_{w}}{A}\right)^{2} \cdot \int_{-h_{o}}^{h_{o}} \mu(z) \cdot \sqrt{1-\left(\frac{z}{h_{o}}\right)^{2}} d z
\end{aligned}
$$

where

$$
\mu(z)=\frac{A_{w}}{J_{y}}\left[\frac{A_{f}}{4}\left(h-t_{f}\right)+t_{w} \cdot \frac{h_{o}^{2}-z^{2}}{2}\right]
$$

\section{The Case $\mathbf{N}_{\mathrm{x}}+\mathbf{M}_{\mathrm{x}}+\mathbf{M}_{\mathrm{y}}$.}

In this case, the analysis is very complicated since it depends on the values of $\mathrm{N}_{\mathrm{x}}$ (and, therefore, on the plastic part of the cross-section) and also on the values of $\mathrm{M}_{\mathrm{y}}$. The paths
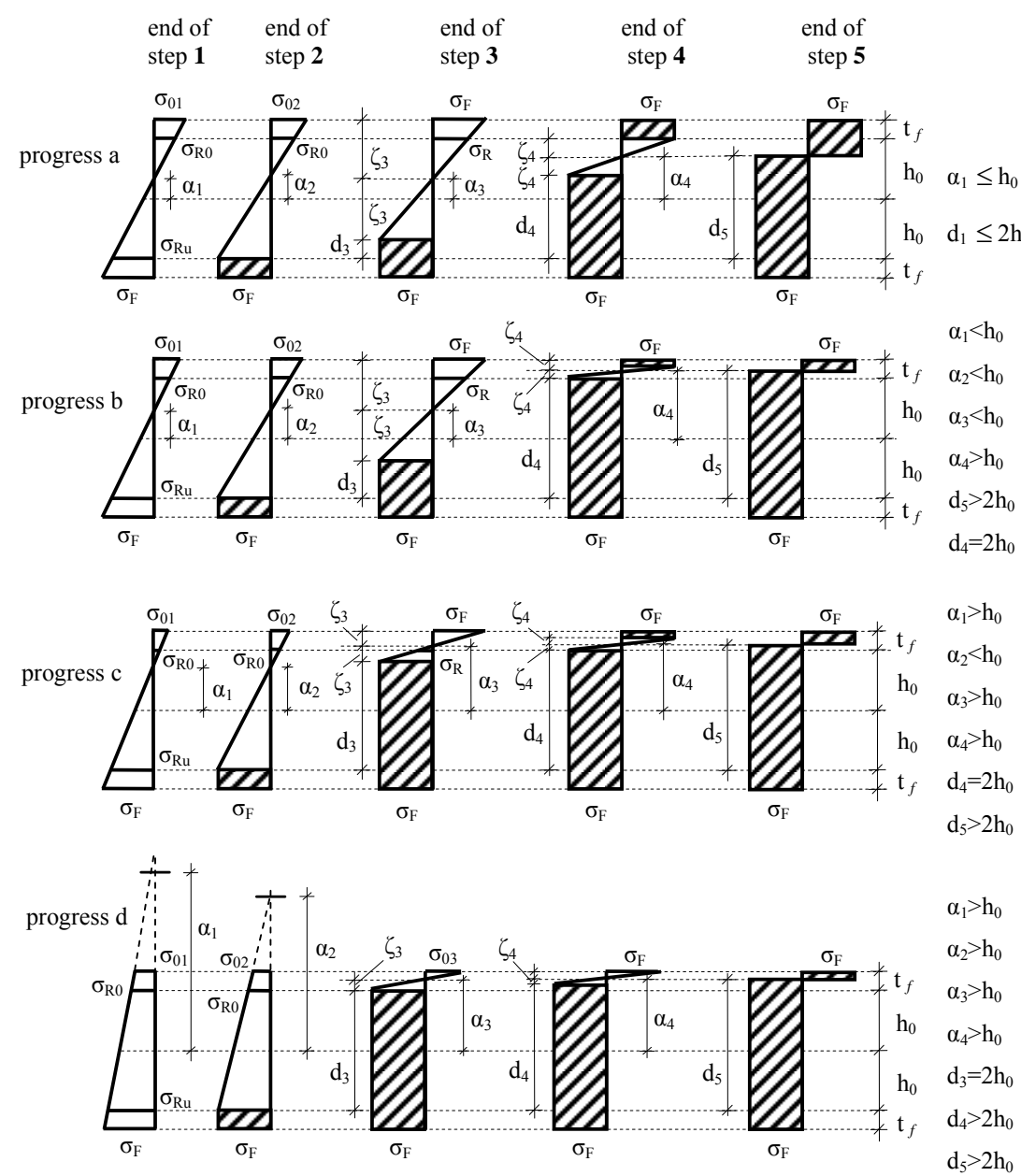

Fig. (9). Plasticization processes for a symmetrical I-section. 
leading to the complete plasticization of the cross-section and the corresponding steps are shown in Fig. (9). The analysis is carried out following the same steps as in the preceding paragraphs and a detailed description is out of the scope of this paper.

\section{NUMERICAL RESULTS \& CONCLUSIONS}

Considering first the simultaneous action of axial force $\mathrm{N}_{\mathrm{x}}$ and torsion moment $\mathrm{M}_{\mathrm{x}}$, we obtain the diagram of Fig. (10) showing the interaction curve $m_{x}-n_{x}$ in nondimensional form. It is observed that for intermediate values of the axial force and the torsion moment the interaction curve is smooth and represents the limiting combinations $\mathrm{N}_{\mathrm{x}}$ $-\mathrm{M}_{\mathrm{x}}$ corresponding to the fully plastic cross-section.

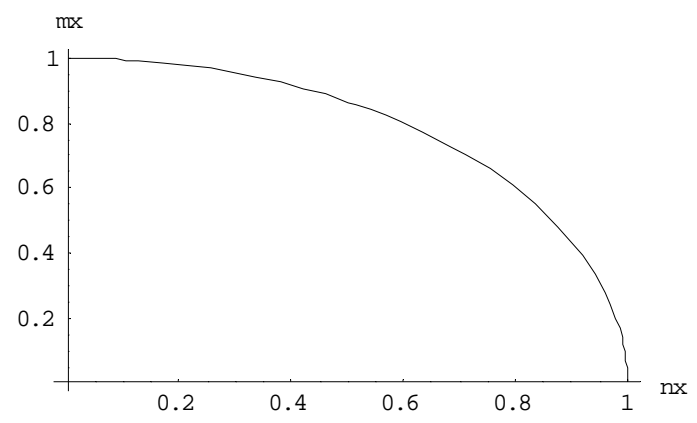

Fig. (10). Interaction curve $m_{x}-n_{x}$.

In Figs (11a) and (11b), one can see the interaction curves $m_{x}-m_{y}$ for HEB and IPE cross-sections, respectively.

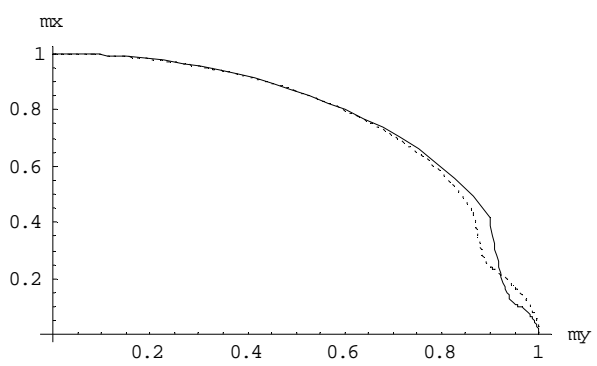

(a)

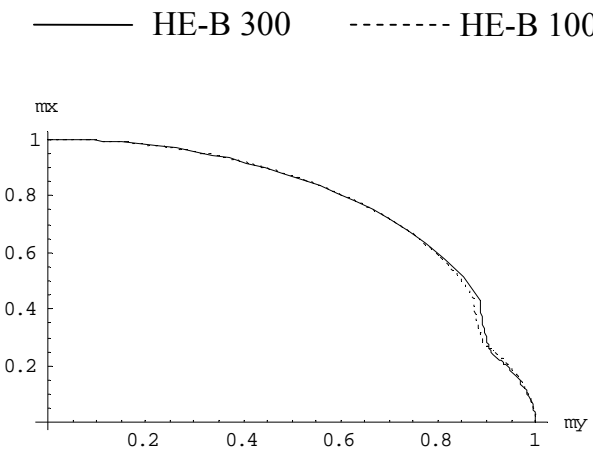

(b)

IPE 300

IPE 1000

Fig. (11). Interaction curves $\mathrm{m}_{\mathrm{x}}-\mathrm{m}_{\mathrm{y}}$ for (a) wide-flange and (b) short-flange I-sections.
It is observed that for small or intermediate values of the bending moment $\mathrm{M}_{\mathrm{y}}$, both interaction curves are smooth and almost coincident, while for higher values of $\mathrm{M}_{\mathrm{y}}$ near the plastic resistance value, a sudden drop is observed on both curves due to phase-chance in the plasticization process accompanied by a $15 \%-20 \%$ difference between the short- and wide-flange I-cross-sections.

The diagram of Fig. (12) shows the interaction curve $m_{x}-$ $\mathrm{m}_{\mathrm{z}}$. One can observe the limited carrying capacity of the Isection in bending moment $\mathrm{M}_{\mathrm{z}}$ and torsion moment $\mathrm{M}_{\mathrm{x}}$ when comparing to the corresponding diagrams $\mathrm{m}_{\mathrm{x}}-\mathrm{m}_{\mathrm{y}}$.

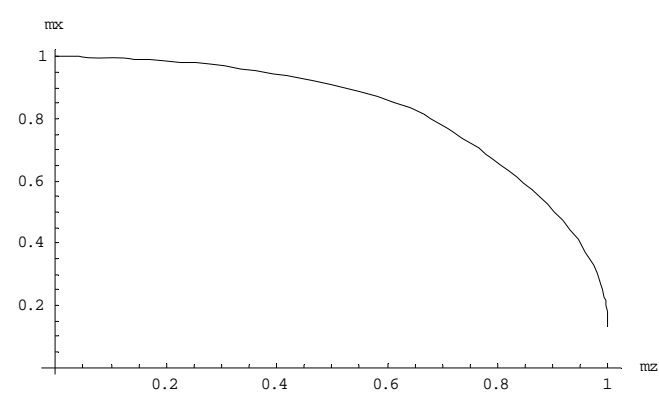

Fig. (12). Interaction curve $m_{x}-m_{z}$.

Fig. (13) shows the interaction curves $\mathrm{m}_{\mathrm{x}}-\mathrm{m}_{\mathrm{y}}$ for different values of the ratio $v=\mathrm{V}_{\mathrm{z}} / \mathrm{V}_{\mathrm{zp}}$. The presence of a shear force $V_{z}$ with simultaneously acting moments $\mathrm{M}_{\mathrm{y}}$ and $\mathrm{M}_{\mathrm{x}}$ causes a gradual reduction of the carrying capacity of the I-section with a maximum $10 \%$ drop.

The interaction curves $\mathrm{v}-\mathrm{m}_{\mathrm{x}}$ are shown in Fig. (14) according to the proposed approach (continuous line) and according to the provisions of EC3-Annex G (doted line). One can observe that EC3 always underestimates the carrying capacity of I-sections leading to uneconomic design. It should be noted at this point that the provisions of Eurocode 3 refer to only this loading case for which, a comparison between the results shows that the code's provisions are partly simplified but certainly uneconomic.

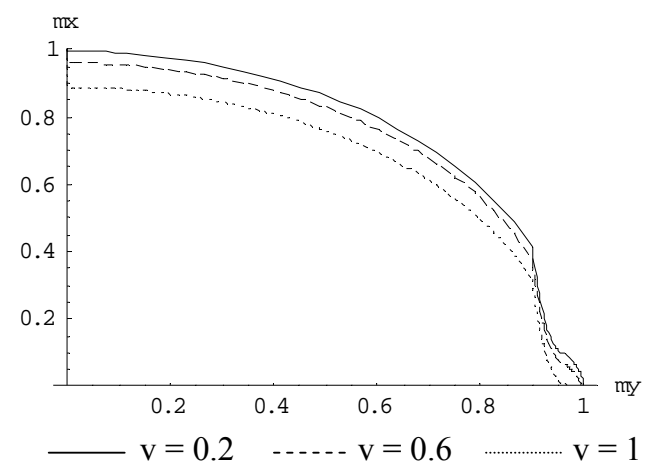

Fig. (13). Interaction curves $m_{x}-m_{y}$ for different values of the ratio $\mathrm{v}=\mathrm{V}_{\mathrm{z}} / \mathrm{V}_{\mathrm{zp}}$.

In Fig. (15), the interaction curves $m_{x}-m_{y}$ are shown for (a) short-flange IPE sections and (b) for wide-flange HEB sections and for different values of the axial force $\mathrm{n}_{\mathrm{x}}$. In both cases, a high reduction of the carrying capacity of the crosssection is observed for high values of the bending moment 


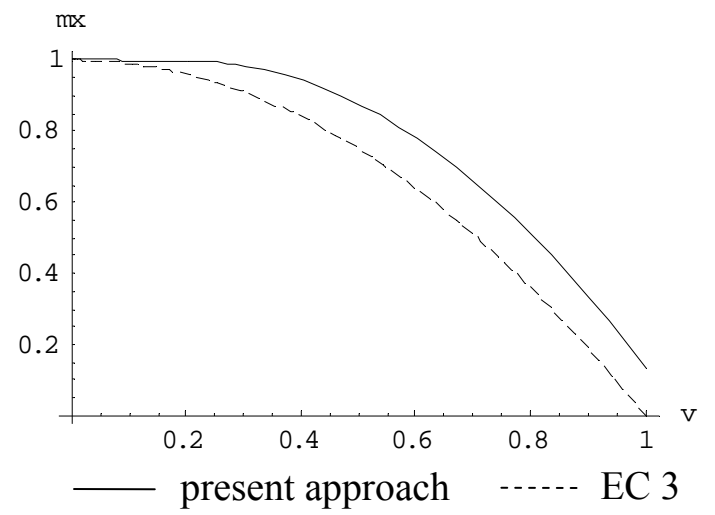

Fig. (14). Interaction curves $m_{x}-v$.

$\mathrm{M}_{\mathrm{y}}$. Also, an additional reduction of the carrying capacity of the I-section with a maximum $15 \%$ drop is observed when a significant axial force $\mathrm{N}_{\mathrm{x}}$ is present.

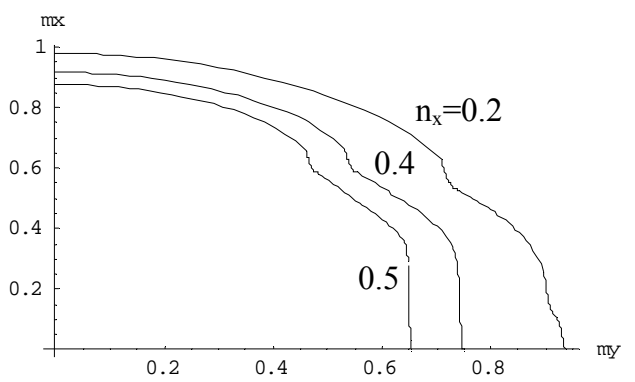

(a) IPE - profiles (short flange)

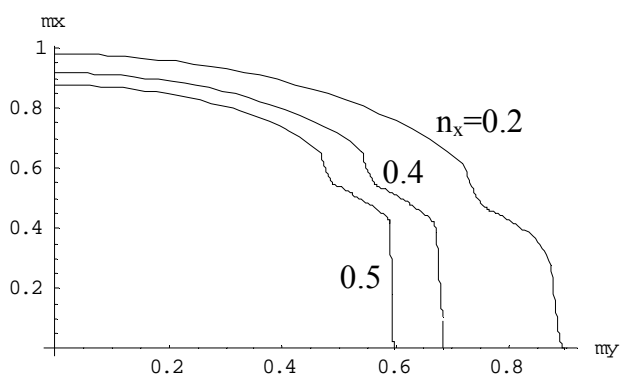

(b) HE-B profiles (wide flange)

Fig. (15). Interaction curves $m_{x}-m_{y}$ for various values of $\mathrm{n}_{\mathrm{x}}=\mathrm{N}_{\mathrm{x}} / \mathrm{N}_{\mathrm{x}, \mathrm{p} \mathrm{l}} \cdot$

Finally, we can conclude that following the present approach one can achieve the fulfillments of a very economic and safe design.

\section{LIST OF SYMBOLS}

$\sigma=$ normal stresses

$\begin{array}{ll}\varepsilon & =\text { normal strains } \\ \tau_{\mathrm{xy}} & =\text { shear stresses } \\ \sigma_{\mathrm{F}} & =\text { yield stress } \\ \Phi & =\text { stress function } \\ \mathrm{F} & =\text { failure criterion } \\ \mathrm{N}_{\mathrm{x}} & =\text { axial force } \\ \mathrm{M}_{\mathrm{x}} & =\text { torsional moment } \\ \mathrm{M}_{\mathrm{y}} & =\text { bending moment about } \mathrm{y} \\ \mathrm{M}_{\mathrm{z}} & =\text { bending moment about } \mathrm{z} \\ \mathrm{e} & =\text { index for sizes in the elastic region } \\ \mathrm{p} & =\text { index for sizes in the plastic region } \\ \mathrm{f} & =\text { index for flange sizes } \\ \mathrm{W} & =\text { index for web sizes } \\ \mathrm{W} & =\text { first moment of inertia } \\ \mathrm{J} & =\text { second moment of inertia } \\ \mathrm{J}_{\mathrm{d}} & =\text { polar moment of inertia } \\ \mathrm{n}_{\mathrm{x}} & =\text { non-dimensional axial force } \\ \mathrm{m}_{\mathrm{x}} & =\text { non-dimensional torsional moment } \\ \mathrm{m}_{\mathrm{y}} & =\text { non-dimensional bending moment about } \mathrm{y} \\ \mathrm{m}_{\mathrm{z}} & =\text { non-dimensional bending moment about } \mathrm{z} \\ \mathrm{v}_{\mathrm{z}} & =\text { non-dimensional shear force along } \mathrm{z} \\ \mathrm{f} & =\mathrm{E}\end{array}$

\section{REFERENCES}

[1] Timoshenko SP. Strength of materials. $2^{\text {nd }}$ ed, New York: Van Nostrand 1940.

[2] Hill R. Theory of plasticity. New York: McGraw-Hill 1952.

[3] Eurocode 3. Design of steel structures, part 1.1 General rules and rules for buildings, European Committee for Standardization. Brussels 2004.

[4] Eurocode 3. Design of steel structures, Part 1.1 Annex G-Design for torsion resistance, European Committee for Standardization, ENV 1993-1-1. Brussels 1998.

[5] Gruttmann F, Saner R, Wagner W. Shear stresses in prismatic beams with arbitrary cross-sections. Int J Numer Methods Eng 1999; 45: 865-89.

[6] Sophianopoulos DS, Michaltsos GT. The effect of thermal residual stresses on the bearing capacity of Hot-Rolled I-sections under combined bending and shearing force. In: EUROSTEEL 2002, $3^{\text {rd }}$ Eropean Conference on Steel Structures Coimbra, Portugal 2002; pp. 173-82.

[7] Zeller C. Zur bestimmung die vervölbung und profilverformungen von elastischen stäben mit beliebigen und dünvandingen qverschnitten. Ingenieur Arch 1985; 55: 376-87.

[8] Kidmann R, Frickel J. Grenztragfähigkeit von I-Querschnitten für beliebige schnittgrößen. Stahlbau 1999; 68: 290-301.

[9] Michaltsos GT, Raftoyiannis IG. Interaction curves of forces and moments of a symmetrical I-cross-section. In: EUROSTEEL 2005 , $4^{\text {th }}$ European Conference on Steel and Composite Structures Maastricht, The Netherlands 2005; 1.8: pp. 9-16.

[10] Sokolnikoff IS. Mathematical theory of elasticity. New York: McGraw-Hill 1956.

Received: November 04, 2009

Revised: January 11, 2010

Accepted: January 18, 2010

(C) Michaltsos and Raftoyiannis; Licensee Bentham Open.

This is an open access article licensed under the terms of the Creative Commons Attribution Non-Commercial License (http://creativecommons.org/licenses/by-nc/3.0/) which permits unrestricted, non-commercial use, distribution and reproduction in any medium, provided the work is properly cited. 